\title{
Evaluation of toxicological profile of methanol leaf extract of Waltheria indica (Sterculiaceae)
}

\author{
Oluwasegun Adedokun 1, *, Ogochukwu Ume 2, Mansurat Odunola 1, Didacus Nnamani 3, Christiana \\ Jesumirhewe ${ }^{4}$, Toluwalope 0jo ${ }^{1}$ and Ifeatu Aniebue ${ }^{1}$ \\ ${ }^{1}$ Department of Pharmacognosy, Igbinedion University, Okada, Edo State, Nigeria. \\ 2 Department of Pharmaceutical Chemistry, Igbinedion University, Okada, Edo State, Nigeria. \\ ${ }^{3}$ Department of Pharmaceutical technology, Igbinedion University, Okada, Edo State, Nigeria. \\ ${ }^{4}$ Department of Pharmaceutical microbiology, Igbinedion University, Okada, Edo State, Nigeria.
}

GSC Biological and Pharmaceutical Sciences, 2021, 17(02), 034-043

Publication history: Received on 06 September 2021;revised on 25 October 2021;accepted on 27 October 2021

Article DOI: https://doi.org/10.30574/gscbps.2021.17.2.0267

\begin{abstract}
Waltheria indica has been claimed to be used in managing several diseases in traditional medicine, although substantial scientific data are not available as regards its safety despite its pronounced efficacy in management of some ailments. Therefore, methanol leaf extract of $W$. indica was evaluated for its effects on some toxicological parameters using experimental animals. However, acute and sub-acute toxicity were carried out using experimental animals as described by standard methods. Absence of death reported after 24 hours of single oral administration of $W$. indica indicated that the crude drug is safe orally and the sample also had no effect on both hematological and biochemical parameters, with mild toxicity observed with some vital enzymes and organs upon continuous oral administration of $W$. indica for 21 days. However, it can be concluded that prolong usage of the plant for disease management should be discouraged, which implies that usage of the pant for short time usage in disease management.
\end{abstract}

Keywords: Acute toxicity; Biochemical parameters; Sub-acute toxicity; W. indica

\section{Introduction}

Medicinal plants are usually regarded as a rich source of chemical entities which can be used in drug development and synthesis. Besides these plants play a critical role in the development of human cultures around the world [1]. Medicinal plants have been discovered for decades and employed in indigenous medicine practices ever since prehistoric times. Hundreds of biochemical compounds are biosynthesized by plants for functions including defense against insects, herbivorous mammals, and microbial attack. However, as a single plant has widely diverse phytochemicals, the effect of using a whole plant as medicine is not certain due to associated toxicity, apart from its inherent biological or pharmacological attributes. Further, the constant development of modern scientific research bioassays and analytic procedures and techniques ae expected to further enhance not only purity and efficacy but also safety of these medicinal plants and their corresponding natural drugs and led compounds [2].

However, A large number of plants can cause adverse effects when ingested by animals or people. Plant toxicity is due to a wide diversity of chemical toxins that include alkaloids, glycosides, proteins and amino acids. There are several notable toxic plants for which a specific chemical responsible for toxicity has not been determined. There are many examples of species differences in terms of their sensitivity to intoxication from plants. Pets, such as dogs and cats, and people, especially children, are frequently exposed to the same toxic plants due to their shared environments [3]. On the other hand, livestock are exposed to toxic plants that are rarely involved in human intoxications due to the unique

\footnotetext{
* Corresponding author: Adedokun Oluwasegun

Department of Pharmacognosy, Igbinedion University, Okada, Edo State, Nigeria.

Copyright ( 12021 Author(s) retain the copyright of this article. This article is published under the terms of the Creative Commons Attribution Liscense 4.0
} 
environments in which they are kept. Fortunately, adverse effects often do not occur or are generally mild following most toxic plant ingestions and no therapeutic intervention is necessary [3]. However, some plants are extremely toxic and ingestion of small amounts can cause rapid death. The diagnosis of plant intoxication can be challenging, especially in veterinary medicine where a history of exposure to a toxic plant is often lacking. Analytical tests are available to detect some plant toxins, although their diagnostic utility is often limited by test availability and timeliness of results. With a few notable exceptions, antidotes for plant toxins are not available. However, general supportive and symptomatic care often is sufficient to successfully treat a symptomatic patient [3].

Waltheria indica (WI) is a common plant used in traditional medicine in Nigeria, usually found in wild and used by locals in preparation of many local medicinal herbs for disease management. The plant is distributed widely in tropical regions of the world and known for its bitter taste and astringent property. Hence, it is used to clear damp heat, poison and to cool blood [4]. However, WI in northern Nigeria is locally called as 'kafafi' in Fulani, 'hankufah' or 'hankubah' in Hausa, 'efu-abe' in Nupe, 'korikodi' in Yoruba [5,6]. It is utilized by native populations in different regions of the globe to treat several pathological conditions due to various classes of secondary metabolites present in the plant. WI have also been reported to be used in management of the following diseases, cataract [7], diabetics [8], asthma [4], anemia [9], male sexual dysfunction [10] and cancer [11].

\section{Material and methods}

\subsection{Laboratory animals}

Swiss albino mice of both sexes (20 - 25 g) were chosen for acute toxicity studies and Wistar albino rats of weight ranging between 150 - $200 \mathrm{~g}$ of both sexes were likewise selected for sub-acute toxicity procedure. The laboratory animals were sourced from Department of Pharmacology animal house and were likewise given free access to food. They were maintained under standard laboratory conditions which included 12-hour light-dark cycle and temperature of $28-30^{\circ} \mathrm{C}$. Moreover, the experimental animals are allowed for two weeks acclimatization period for adaptation prior to the entire toxicity studies. The experimental protocol was initially approved by the IAEC (Institutional Animal Ethical Committee) prior to carrying out of the entire experimental activities and care of the laboratory animals were carried out using the CPCSEA guidelines.

Acute and sub-acute toxicity studies were carried out on the extract as explained below:

\subsection{Acute Toxicological Study}

Lethal doses ( $\mathrm{LD}_{50}$ ) of the crude extracts were examined using 48 mice (consisting of both male and female weighing 20 - $25 \mathrm{~g}$ ) for each extract. They were fed with standard rat pelleted diet (Bendel feeds, Edo state, Nigeria) and water ad-libitium and maintained under hygienic standard laboratory condition in animal house of Department of Pharmacology, Faculty of Pharmacy, and University of Benin, Nigeria. The experiment was initiated only after the approval of the Animal Ethics Committee of Faculty of Pharmacy, University of Benin. Single and daily oral doses of 50, $100,300,500,1000$ and $5000 \mathrm{mg} / \mathrm{kg}$ of the extracts were administered to six groups of animals (each consisting of seven animals) while 5\% Tween-80 were administered to the control group. The mice were observed continuously for $1 \mathrm{hr}$ for any gross behavioural changes and deaths and intermittently for the next 6 hours and then again at $48 \mathrm{hrs}$ after dosing. Survival animals were kept under observation for 7 days.

\subsection{Sub-Acute toxicity}

Rats were grouped into four (4), namely: A, B, C and D. However, the animals in group A which served as the control were orally administered with $1 \mathrm{~mL}$ of distilled water while those in groups $\mathrm{B}, \mathrm{C}$ and D received orally extract of $W$. indica at doses of 250, 500 and $1000 \mathrm{mg} / \mathrm{kg}$ body weight respectively. The administration was done once daily. The animals were handled according to the guidelines of [12]. The animals were sacrificed 21 days of administration of the crude extract. The blood of the animals was used for both biochemical and hematology analysis while histopathology studies of the liver and kidney were carried out.

\subsubsection{Preparation of serum and plasma}

The rats were anaesthetized in a jar containing cotton wool soaked in chloroform. Blood samples were collected (via cardiac puncture) into sample bottles and allowed to clot at room temperature for 20 minutes and thereafter centrifuged at $1398 \mathrm{x}$ rpm for 15 minutes. Clear colorless serum was collected with the aid of Pasteur pipette. Moreover, plasma obtained after centrifugation of heparinized blood was used for hematological analysis. 


\subsubsection{Biochemical analysis}

Biochemical analyses were performed on serum obtained after centrifugation of whole blood (without anticoagulant) at $3000 \mathrm{rpm}$ for $5 \mathrm{~min}$. The following biochemical analyses were carried out.

Kidney function test

\section{A) Assay for Urea}

This test exploits the hydrolysis of urea to ammonia in the presence of urease enzyme. $100 \mu \mathrm{L}$ of reagent 1 was added to $10 \mu \mathrm{L}$ serum samples in test tubes. $100 \mu \mathrm{L}$ of reagent 1 was also added to $10 \mu \mathrm{L}$ distilled water to serve as blank. Solutions in the test tubes being thoroughly mixed for incubation at 10 minutes of $37^{\circ} \mathrm{C} .2 .5 \mathrm{~mL}$ of reagents 2 and 3 drops were added in each test tube. Solutions in test tubes were mixed and further incubated for 10 minutes at $37{ }^{\circ} \mathrm{C}$. Absorbances of samples and standard were read against the blank using the wavelength of $546 \mathrm{~nm}$. Urea values were calculated as thus.

Urea concentration $(\mathrm{mg} / \mathrm{dL})=$ Absorbance of sample/ Absorbance of standard $\mathrm{x} 80$.

\section{b) Assay for Creatinine}

This test exploits the reaction of creatinine present in alkaline mixture using picric acid to produce colored complex. The quantity of complexity formed is directly proportional to creatinine concentration. $0.2 \mathrm{~mL}$ sample macro and semi micro was added to the test tube. $0.2 \mathrm{~mL}$ standard macro and $0.1 \mathrm{~mL}$ semi micro were added to the standard solution test tube. $2 \mathrm{~mL}$ of standard macro, $1 \mathrm{~mL}$ of semi micro, $2 \mathrm{~mL}$ of sample macro and $1 \mathrm{~mL}$ of semi micro were added to the working reagent test tube. The solutions in the test tubes were mixed. The absorbances of the samples and standard were measured at $492 \mathrm{~nm}$. Creatinine concentration being calculated as thus:

Creatinine concentration units $(\mathrm{mg} / \mathrm{dl})=$ Absorbance of sample/Absorbance of standard x 2 .

c) Assay for Electrolytes (Sodium, chloride, bicarbonate and potassium)

\section{Bicarbonate}

The assay for bicarbonate exploits the reaction between bicarbonate ions with dilute hydrochloric acid to yield carbon dioxide. The excess acid is titrated with dilute sodium hydroxide using phenol red as indicator. $0.01 \mathrm{~N} \mathrm{HCl}$ was added to $200 \mu \mathrm{L}$ of serum sample. The solution was mixed and 1 drop of phenol red indicator added. The solutions were titrated using $0.01 \mathrm{~N}$ sodium hydroxide to attain brick red colouration which serves as endpoint [13].

Bicarbonate was calculated as thus: Bicarbonate $(\mu \mathrm{mol} / \mathrm{l})=50-$ Titre

Titre $=$ Endpoint $\mathrm{x} 100$.

\section{Chloride}

The assay for chloride exploits the formation of chloride precipitate in a sample using mercuric nitrate. When chloride is titrated with standard solution of mercuric ion, undissociated but stable mercuric chloride is formed. The excess mercuric chloride nitrate reacts with diphenylcarbazone to produce a violet coloration. $2 \mathrm{~mL}$ of deionized water was added to $200 \mu \mathrm{l}$ serum sample. This solution was mixed thoroughly and 3 drops diphenylcarbazone indicator and 1 drop of nitric acid was added. The mixture was titrated via mercuric nitrate to give a violet endpoint. The same procedure was repeated for chloride standard solution [14]

Chloride calculation such as:

Chloride $(\mu \mathrm{mol} / \mathrm{l})=$ Titre of sample $/$ Title of standard $\mathrm{x} 100$.

Sodium and potassium

The assay method for sodium and potassium entails the injection of solutions containing these elements in flame leaving solid salt, which dissociates to neutral ground state. The atoms become excited in the flame, thus moving to a higher energy state. The excited atoms then fall back to ground state emitting light of characteristic wavelength $(590 \mathrm{~nm}$ 
sodium and $770 \mathrm{~nm}$ potassium). The light surpasses through viable filter onto photosensitive element while, the quantity of current flows was relatively the amount of potassium and sodium found in serum sample [15]

d)Determination of Serum Total Bilirubin and Unconjugated Bilirubin

Total bilirubin can be anticipated via acid diazo technique as illustrate by [16], by assay kits (Randox Laboratories Ltd).

Principle

Sulphanilic acid can be diazotized using nitrous acid synthesized from reaction involving hydrochloric acid (HCL) and sodium nitrite $\left(\mathrm{NaNO}_{2}\right)$. Direct conjugated bilirubin interacts with diazotised sulphanilic acid to produce azobilirubin. Pink acid (azobilirubin) can be changed to blue acid (azobilirubin) using alkaline tartrate. Total bilirubin usually can be resolute in caffeine presence, which liberates albumin hurdle bilirubin via response to diazotized sulphanilicate. Unconjugated bilirubin can be through their differences.

Procedure

Total bilirubin;at precisely, $0.05 \mathrm{~mL}$ reagent 2 , composed of sodium nitrate $\left(\mathrm{NaNO}_{2}\right)$ being placed into test tubes enclosed with $0.2 \mathrm{~mL}$ of the reagent 1 , composed of hydrochloric acid and sulphanilic acid of $1.0 \mathrm{~mL}$ reagent 3 , has sodium benzoate and caffeine was added with $0.2 \mathrm{~mL}$ of serum, thoroughly mixed and kept in a place for 10 minutes room temperature. Reagent $4(1 \mathrm{~mL})$, have tartarate, also sodium hydroxide $(\mathrm{NaOH})$ was added, properly mixed and kept for 10 minutes room temperature. Absorbance of samples against blank (ATB) was measured using wavelength of $560 \mathrm{~nm}$ in spectrophotometer. Calculations

Total bilirubin $(\mathrm{mg} / \mathrm{dl})=10.8 \times$ ATB

Unconjugated bilirubin units $(\mathrm{mg} / \mathrm{dl})=10.8 \times$ Absorbance of total bilirubin (ATB) $-14.4 \times$ Absorbance of direct bilirubin (ADB)

Liver function test

A volume of blood from each rat was put into plain bottles and allowed to clot at room temperature for 4 hours before centrifuging using Hettich centrifuge at $4000 \mathrm{rpm}$ for 10 minutes. The sera obtained were used to assay for liver function test endpoints using standard diagnostic kits on automated clinical system in line with manufacturer instructions. Assays were carried out as follows:

Determination of Serum Alanine Aminotransferase (ALT)

The serum alanine aminotransferase was determined as described by Reitman and frankel (1957) using end-point technique.

Assay principle

$\alpha$-Oxoglutarate + L-alanine $\stackrel{\text { ALT }}{\longrightarrow}$ L-glutamate + pyruvate

Alanine aminotransferase is measured by monitoring the concentration of pyruvate hydrazone formed with 2 , 4dinitrophenylhydrazine at $540 \mathrm{~nm}$ and $37^{\circ} \mathrm{C}$.

Procedure

Exactly, $0.5 \mu \mathrm{L}$ of reagent 1 which is made up of phosphate buffer, L-alanine and $\alpha$-oxoglutarate was added in a clean test tube containing $0.1 \mathrm{~mL}$ of serum, mixed and 43 incubated for exactly 30 minutes at $37^{\circ} \mathrm{C} .0 .5 \mathrm{~mL}$ of reagent 2 which is made up of 2, 4-dinitrophenylhydrazine was added, mixed and allowed to stand for exactly 20 minutes at $20-25^{\circ} \mathrm{C}$. Then $0.5 \mathrm{~mL}$ of sodium hydroxide solution was added, mixed and absorbance was read against the blank (also prepared) at $540 \mathrm{~nm}$ after 5 minutes. The ALT concentration (U/L) was determined from the standard calibration table provided in the manual of Randox Lab. Ltd, UK Reagent Kit. 
Determination of Serum Aspartate Aminotransferase (AST)

The serum aspartate aminotransferase was determined as described by [17] using end-point technique.

Assay Principle

$\alpha$-Oxoglutarate + L-aspartate $\longrightarrow$ AST $\longrightarrow$ L- glutamate + Oxaloacetate

Aspartate aminotransferase is measured by monitoring the concentration of oxaloacetate hydrazone formed with of 2 , 4-dinitrophenylhydrazine using $540 \mathrm{~nm}$ at $37^{\circ} \mathrm{C}$.

Procedure

Exactly, $0.5 \mu \mathrm{L}$ of reagent 1 , made up of phosphate buffer, L-aspartate and $\alpha$-oxoglutarate were added to a test tube containing $0.1 \mathrm{~mL}$ of serum, mixed and incubated for exactly 30 minutes at $37^{\circ} \mathrm{C}$. $0.5 \mathrm{~mL}$ of reagent 2 , made up of $2,4-$ dinitrophenylhydrazine was added, mixed and allowed to stand for exactly 20 minutes at 20-250C. Then $0.5 \mathrm{~mL}$ of sodium hydroxide solution was added, mixed and absorbance was read against the blank (also prepared) at 540nm after 5 minutes. The AST concentration (U/L) was determined from the standard calibration table provided in the manual of Randox Lab. Ltd, UK Reagent Kit.

Determination of Serum Alkaline Phosphatase (ALP)

The procedure described by [18] as modified by [19] using Randox kits was used for the assay.

The substrate p-nitrophenyl phosphate is hydrolyzed by alkaline phosphatase from the sample in the presence of magnesium ions, to form nitrophenol which is yellow and can be 42 read at $405 \mathrm{~nm}$. The intensity of color produced is proportional to the activity of alkaline phosphatase.

Principle

Para-nitrophenylphosphate $+\mathrm{H} 2 \mathrm{O} \longrightarrow$ phosphate + para-nitrophenol

Alkaline phosphatase is measured by monitoring the concentration of phosphate hydrazone formed with 2, 4dinitrophenylhydrazine at $405 \mathrm{~nm}$ and $37^{\circ} \mathrm{C}$.

Procedure

In a cuvette, $10 \mu \mathrm{L}$ of sample was mixed with $500 \mu \mathrm{L}$ of the reagent. The initial absorbance was read at $405 \mathrm{~nm}$, and subsequently over 3 minutes. The mean absorbance per minute was used in the calculation.

\subsection{Hematological parameters}

The heparinized blood was used for the analysis of hematological parameters such as hemoglobin, red blood cell count, white blood cell count, platelet count was measured using fully automated hematology analyzer (PE 6000)

\subsection{Histological study}

The organs (Liver, Kidney and heart) were carefully removed and weighed individually and fixed in 10\% (vol/ vol) formaldehyde, cleaned up in xylene and embedded in a paraffin wax (melting point at 56 percent). Tissue sections were prepared according to the method of [20] and stained with eosin/ hematoxylin. Photomicrographs were taken at $\times 400$ using a digital camera.

\subsection{Statistical analysis}

The statistical significance was evaluated by analysis of variance (ANOVA) followed by Dunnett's test. P values $\leq 0.05$ were considered to be statistically significant. The experiments were carried out in six replicates and results are presented as mean \pm standard error of the mean (Mean \pm SEM). 


\section{Results and discussion}

Toxicological tests are carried out to ascertain the safety of plant material. Different analyses were carried out on $W$. indica to analyze the toxicological profile of the methanol extract of $W$. indica and results are obtained are shown below:

\subsection{Acute toxicity of $W$. indica}

The behavior parameters observed were wobbling, hyperactivity and increased respiration.

The LD $50>5000 \mathrm{mg} / \mathrm{kg}$ when both extracts were orally administered, since no animal died at $5 \mathrm{~g} / \mathrm{kg}$ (highest dose administered). Therefore, both plants were noted to be safe orally.

\subsection{Sub-acute toxicity study of $W$. indica}

Based on the biochemical analyses, no significance was observed in any of the biochemical parameters in the kidney function test when different doses of methanol extracts of $W$. indica were administered to the animals. This indicates that the methanol extracts of $W$. indica has no toxic biochemical effect on the kidney s shown in Table 1 below.

However, the results showing the effect of $W$. indica on some vital enzymes and hematological parameters after administration for 21 days are shown in Table 2 and 3 respectively.

Table 1 Effect of Walteria indica on biochemical parameters of rats after 21 days of administration

\begin{tabular}{|l|c|c|c|c|}
\hline \multirow{2}{*}{ Biochemical parameters } & \multicolumn{4}{|c|}{ Doses } \\
\cline { 2 - 5 } & Control (Distilled water) & $\mathbf{1 0 0} \mathbf{~ m g} / \mathbf{k g}$ & $\mathbf{2 0 0} \mathbf{~ m g} / \mathbf{k g}$ & $\mathbf{4 0 0} \mathbf{~ m g} / \mathbf{k g}$ \\
\hline $\mathrm{Na}(\mathrm{mmol} / \mathrm{l})$ & $125.00 \pm 2.38$ & $118.00 \pm 4.19$ & $136.30 \pm 4.89$ & $139.10 \pm 4.71$ \\
\hline $\mathrm{K}(\mathrm{mmol} / \mathrm{l})$ & $13.20 \pm 2.17$ & $14.50 \pm 4.52$ & $15.60 \pm 5.90$ & $16.70 \pm 3.75$ \\
\hline $\mathrm{Cl}(\mathrm{mmol} / \mathrm{l})$ & $81.41 \pm 3.55$ & $95.50 \pm 4.89$ & $99.80 \pm 4.26$ & $89.50 \pm 3.85$ \\
\hline Bicarbonate $(\mathrm{mmol} / \mathrm{l})$ & $28.20 \pm 2.10$ & $28.60 \pm 2.99$ & $27.30 \pm 4.11$ & $31.70 \pm 3.28$ \\
\hline Urea (mg/dl) & $22.40 \pm 1.66$ & $24.90 \pm 2.80$ & $37.60 \pm 4.24$ & $29.89 \pm 5.27$ \\
\hline Creatinine (mg/dl) & $0.20 \pm 0.11$ & $0.20 \pm 0.11$ & $0.20 \pm 0.19$ & $0.10 \pm 0.02$ \\
\hline Total Bilirubin (mg/dl) & $0.10 \pm 0.04$ & $0.30 \pm 0.05$ & $0.20 \pm 0.08$ & $0.20 \pm 0.11$ \\
\hline Direct Bilirubin (mg/dl) & $0.15 \pm 0.09$ & $0.10 \pm 0.08$ & $0.10 \pm 0.04$ & $0.20 \pm 0.02$ \\
\hline Indirect Bilirubin (mg/dl) & $0.10 \pm 0.06$ & $0.20 \pm 0.13$ & $0.10 \pm 0.02$ & $0.10 \pm 0.02$ \\
\hline
\end{tabular}

The values above are mean of six replicates. $n=6$. Mean \pm SEM. Dose with no superscript $\left(^{*}\right)$ indicate no significant difference at $\mathrm{P}<0.05$ when compared to mean of control for each biochemical enzymes using one-way ANOVA (Kruskal - Wallis test).

However, no significant difference in the alkaline phosphate, AST/SGOT and ALT/SGPT at $250 \mathrm{mg} / \mathrm{kg}$ and $500 \mathrm{mg} / \mathrm{kg}$ respectively when compared with the amount of the enzymes obtained from animals administered with the vehicle (control; $10 \mathrm{~mL} / \mathrm{kg}$ ). An increase in the dose to $1000 \mathrm{mg} / \mathrm{kg}$ shows a significant difference in the alkaline phosphate but no significant difference in the AST/SGOT and ALT/SGPT when compared with the amount of the enzymes obtained from animals administered with the vehicle (control; $10 \mathrm{~mL} / \mathrm{kg}$ ). Increase in the alkaline phosphate indicates that a high dose the methanol extract of W. indica maybe hepatotoxic.

The methanol extract of $W$. indica shows no significant effect on the blood cells which indicates that the methanol extract of $W$. indica is not toxic from hematological point of view.

The values above are mean of six replicates. $n=6$. Mean \pm SEM. Doses with no superscript * indicate no significant difference at $\mathrm{P}<0.05$ when compared to mean of control (for each hematological parameter using one-way ANOVA (Kruskal - Wallis test). 
Table 2 Effect of $W$. indica on biochemical enzymes in sub-acute toxicity using rats

\begin{tabular}{|l|cc|c|c|}
\hline \multirow{2}{*}{ Liver enzymes } & \multicolumn{4}{c}{ Doses } \\
\cline { 2 - 5 } \multicolumn{1}{c|}{ Control $\mathbf{( 1 0} \mathbf{~} \mathbf{~ L} / \mathbf{k g})$} & $\mathbf{2 5 0} \mathbf{~ m g} / \mathbf{k g}$ & $\mathbf{5 0 0} \mathbf{~ m g} / \mathbf{k g}$ & $\mathbf{1 0 0 0} \mathbf{~ m g} / \mathbf{k g}$ \\
\hline Alkaline Phosphate & $142.90 \pm 10.31$ & $141.00 \pm 23.51$ & $211.20 \pm 11.41$ & $289.97 \pm 12.11^{*}$ \\
\hline AST/SGOT & $78.60 \pm 7.19$ & $72.67 \pm 6.29$ & $69.61 \pm 13.38$ & $67.68 \pm 11.76$ \\
\hline Difference at P<0.05 when compared to mean of control for each liver enzyme using one way ANOVA (Kruskal - Wallis test).
\end{tabular}

Table 3 Effect of W. indica on hematological parameter in sub-acute toxicity study using rats

\begin{tabular}{|l|c|c|c|c|}
\hline \multirow{2}{*}{ Haematological Parameter } & \multirow{2}{*}{ Control } & \multicolumn{3}{|c|}{ W. indica } \\
\cline { 3 - 5 } & & $\mathbf{1 0 0} \mathbf{~ m g} / \mathbf{k g}$ & $\mathbf{2 0 0} \mathbf{~ m g} / \mathbf{k g}$ & $\mathbf{4 0 0} \mathbf{~ m g} / \mathbf{k g}$ \\
\hline WBC & $142.41 \pm 8.22$ & $148.41 \pm 8.72$ & $147.20 \pm 4.28$ & $197.50 \pm 2.32$ \\
\hline LY & $77.98 \pm 6.29$ & $78.65 \pm 4.22$ & $78.52 \pm 4.29$ & $55.55 \pm 3.16$ \\
\hline MO & $25.37 \pm 6.61$ & $24.89 \pm 6.77$ & $23.89 \pm 3.29$ & $28.53 \pm 6.39$ \\
\hline GR & $122.34 \pm 8.99$ & $129.78 \pm 5.88$ & $135.31 \pm 18.18$ & $141.23 \pm 13.29$ \\
\hline LY\% & $12.77 \pm 3.67$ & $13.91 \pm 5.86$ & $13.50 \pm 4.89$ & $13.90 \pm 5.42$ \\
\hline MO\% & $92.82 \pm 8.70$ & $96.27 \pm 7.25$ & $94.64 \pm 9.22$ & $88.50 \pm 4.28$ \\
\hline GR\% & $27.11 \pm 2.30$ & $31.45 \pm 5.10$ & $25.90 \pm 6.23$ & $27.34 \pm 7.13$ \\
\hline RBC & $37.23 \pm 4.18$ & $29.25 \pm 1.82$ & $39.51 \pm 1.22$ & $29.23 \pm 3.11$ \\
\hline Hgb & $0.25 \pm 0.05$ & $0.22 \pm 0.10$ & $0.28 \pm 0.12$ & $0.31 \pm 0.12$ \\
\hline HCT & $0.20 \pm 0.01$ & $0.20 \pm 0.14$ & $0.20 \pm 0.12$ & $0.20 \pm 0.11$ \\
\hline MCV & $0.03 \pm 0.01$ & $0.10 \pm 0.01$ & $0.10 \pm 0.01$ & $0.20 \pm 0.11$ \\
\hline MCH & $0.10 \pm 0.03$ & $0.10 \pm 0.02$ & $0.10 \pm 0.01$ & $0.10 \pm 0.01$ \\
\hline
\end{tabular}

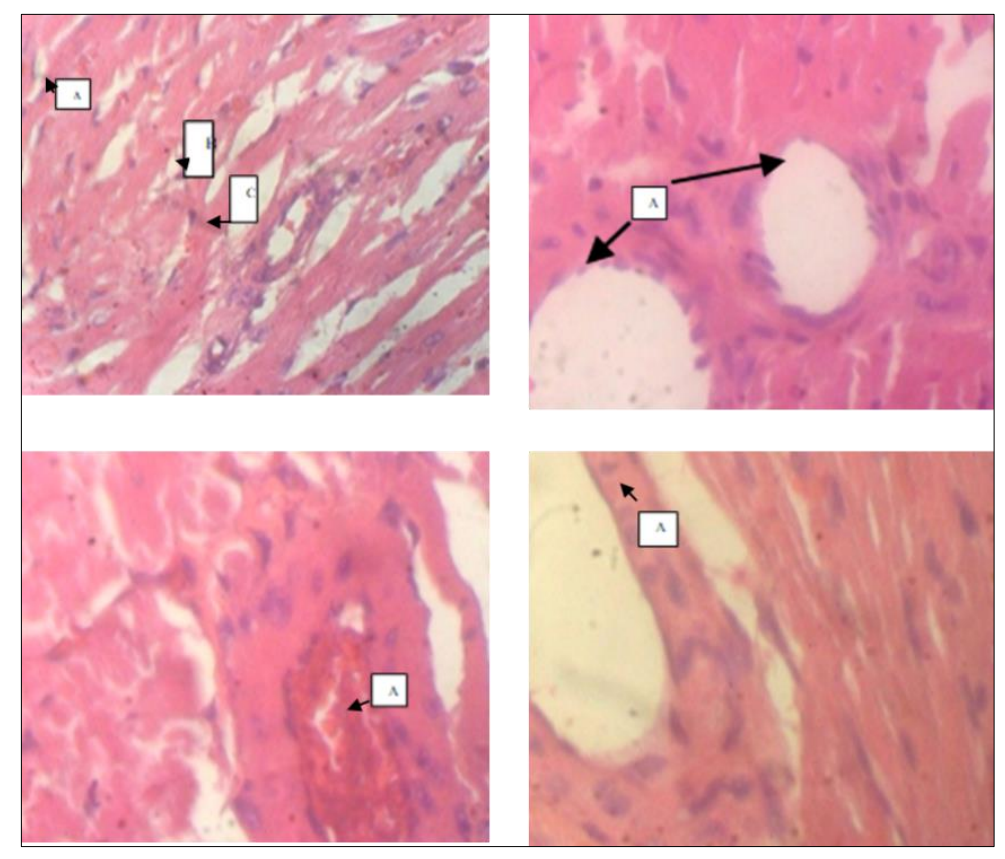

Figure 1 (A) Control Rat heart composed of;A, bundles of myocardiac fibres, B, coronary vessel and C, interstitial space, (B) $250 \mathrm{mg} / \mathrm{kg}$ crude extract of W. indica showed A, moderate vascular dilation, (C) $500 \mathrm{mg} / \mathrm{kg}$ crude extract of W. indica showed A, moderate vascular congestion, and (D) $1000 \mathrm{mg} / \mathrm{kg}$ crude extract of W. indica showed A, moderate vascular dilatation (H\&E) at day 21 
Histological examination of the methanol extract of $W$. indica shows some histopathological changes on the various organs (heart, spleen, liver and kidney) examined. Some of these changes includes: the dilation of bundles of myocardiac fibres in the heart at $100 \mathrm{mg} / \mathrm{kg}$ and $250 \mathrm{mg} / \mathrm{kg}$ and congestion of the vessels at $500 \mathrm{mg} / \mathrm{kg}$ and mild follicular atrophy in the spleen at $250 \mathrm{mg} / \mathrm{kg}$, a mild vascular congestion and moderate Kupffer cell activation in the liver and a mild interstitial congestion in the kidney. These histopathological changes maybe as a result of the secondary metabolites present in the plant.

However, the administration of graded doses of $W$. indica over a period of 21 days caused dilation of bundles of myocardiac fibres at both 250 and $100 \mathrm{mg} / \mathrm{kg}$ while $500 \mathrm{mg} / \mathrm{kg}$ induced congestion of the vessels when compared with the normal control as shown in Figure 1.

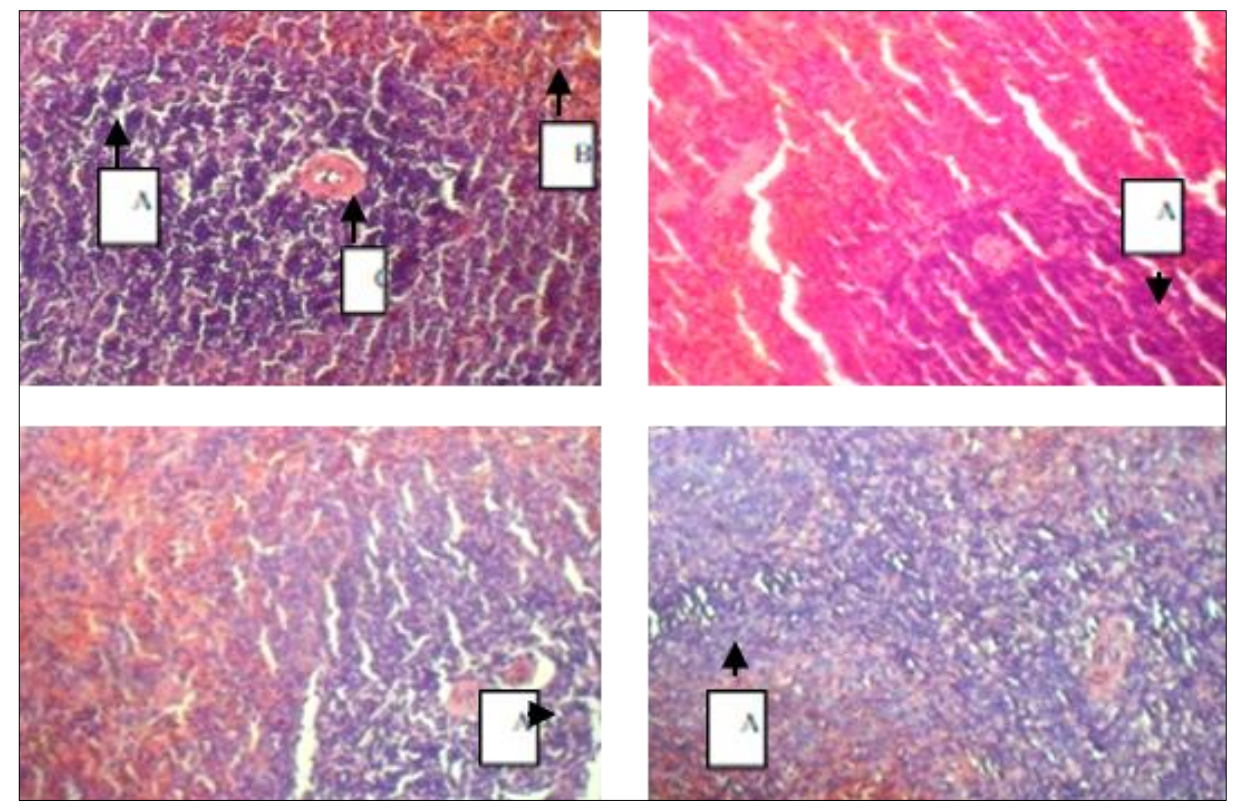

Figure 2 (A) Control Rat spleen composed of A, white pulp, B, red pulp and C, arteriole,(B) $250 \mathrm{mg} / \mathrm{kg}$ crude extract of

$W$. indica showed A, mild follicular atrophy, (C) $500 \mathrm{mg} / \mathrm{kg}$ crude extract of $W$. indica showed A, normal follicular architecture and (D) $1000 \mathrm{mg} / \mathrm{kg}$ crude extract of $W$. indica showed Anormal follicular architecture (H\&E x 100) at day
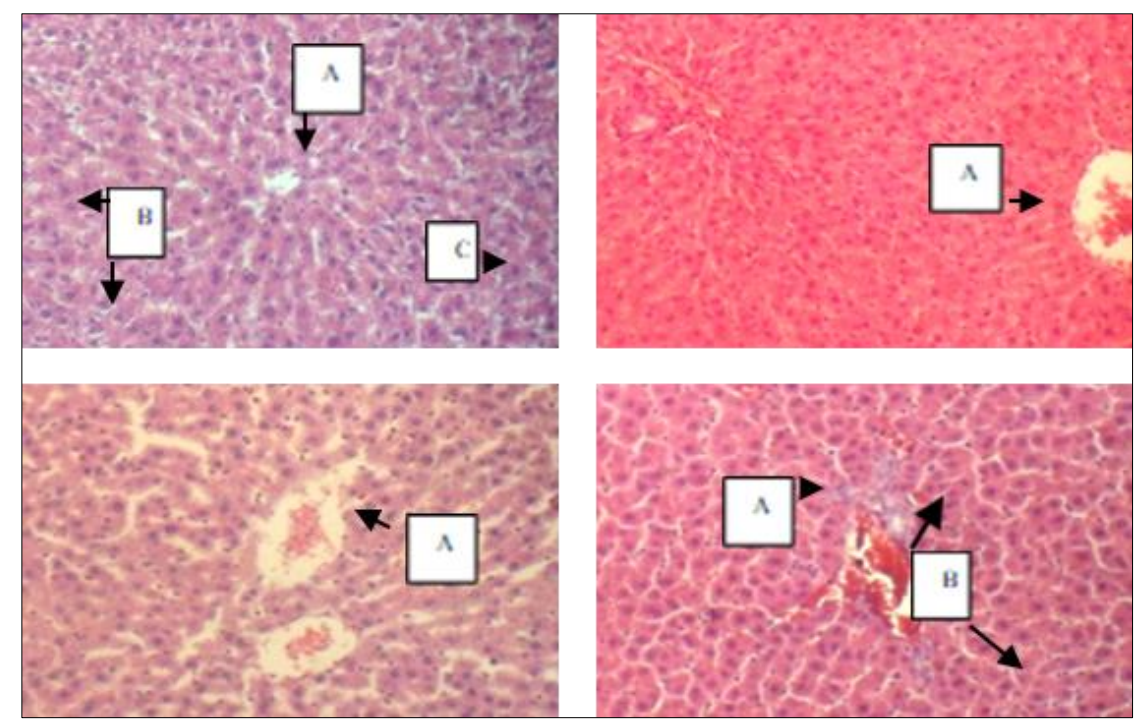

Figure 3 (A) Control Rat liver composed of A, central vein, B, hepatocytes and C, sinusoids, (B) $250 \mathrm{mg} / \mathrm{kg} \mathrm{crude}$ extract of $W$. indica showed: A, mild vascular congestion, (C) $500 \mathrm{mg} / \mathrm{kg}$ crude extract of $W$. indica showed: A, mild vascular congestion and (D) $1000 \mathrm{mg} / \mathrm{kg}$ crude extract of $W$. indica showed A, mild vascular congestion and B, moderate Kupffer cell activation (H\&E x 100) of hepatocytes. 
In addition, administration of $250 \mathrm{mg} / \mathrm{kg}$ of plant extract resulted into a mild follicular atrophy induced when administered for 21 days. Moreover, normal follicular architecture was observed at 500 and $100 \mathrm{mg} / \mathrm{kg}$ when compared with normal control at day 21 as shown in Figure 2.

The administration of graded doses of crude extract of $W$. indica induced mild vascular congestion and moderate Kupffer cell activation to the liver when compared with Control as shown in Figure 3

The administration of graded doses of crude extract of $W$. indica induced mild interstitial congestion in the kidney when compared with Control (distilled water) as shown in Figure 4 below

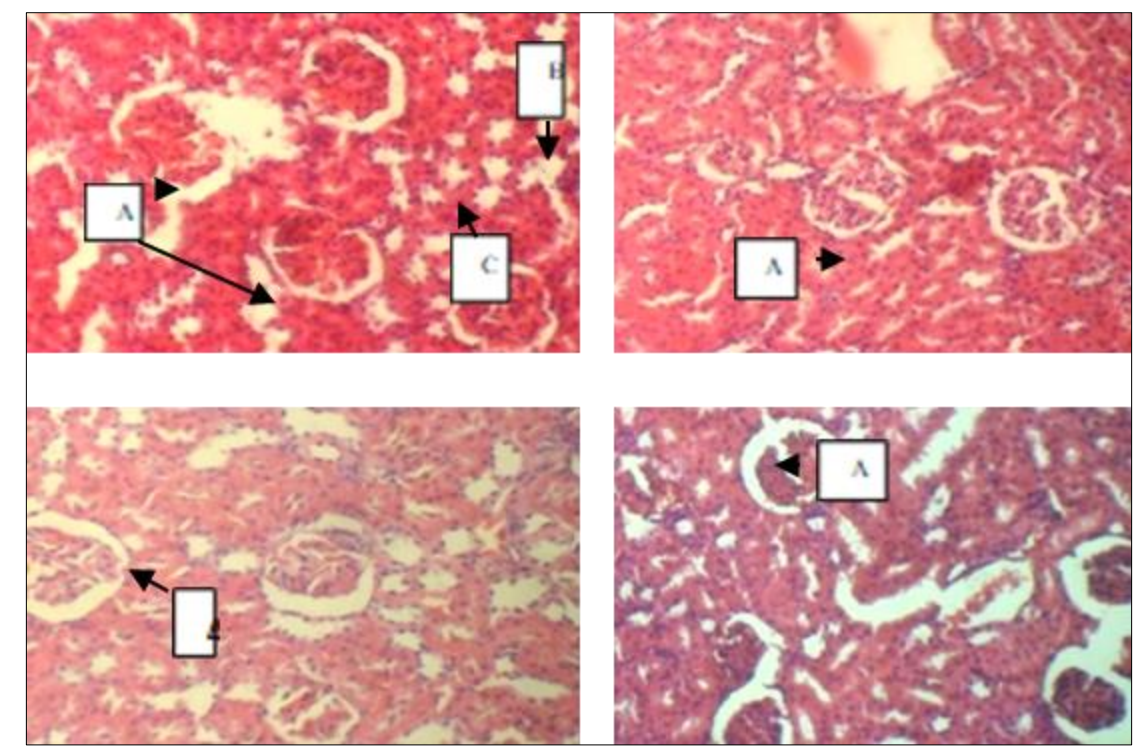

Figure 4 (A) Control Rat kidney composed of A, glomerulus, B, tubules and C, interstitial space, (B) $250 \mathrm{mg} / \mathrm{kg} \mathrm{crude}$ extract of $W$. indica showed A, mild interstitial congestion, (C) $500 \mathrm{mg} / \mathrm{kg}$ crude extract of $W$. indica showed A, mild interstitial congestion and (D) $1000 \mathrm{mg} / \mathrm{kg}$ crude extract of $W$. indica showed A, mild interstitial congestion (H\&E x 100) in kidney

\section{Conclusion}

The study has shown that $W$. indica leaf possess no toxic effect on blood parameters and kidney but mild toxicity was observed on some key serum enzymes as well as organs upon prolong days of administration. However, it can be concluded that prolong usage of the plant for disease management should be discouraged.

\section{Compliance with ethical standards}

\section{Acknowledgments}

The Authors are grateful to the entire staff of Department of Pharmacognosy and Pharmaceutical chemistry, College of Pharmacy, Igbinedion University, Okada, Nigeria for their assistance during this research.

\section{Disclosure of conflict of interest}

No conflict of interest.

\section{References}

[1] Rasool Hassan BA. Medicinal Plants (Importance and Uses). Pharmaceut Anal Acta. 2012; 3: e139.

[2] Ahn K. The worldwide trend of using botanical drugs and strategies for developing global drugs. BMB Reports. 2017; 50 (3): 111-116. 
[3] Poppenga RH. Poisonous plants. In: Luch A. (eds) Molecular, Clinical and Environmental Toxicology. Experientia Supplementum. 2010; 100.

[4] Zongo F, Ribuot C, Boumendjel A, Guissou I. Bioguidage search of active compounds from Waltheria indica L. (Malvaceae) used for asthma and inflammation treatment in Burkina Faso. Fundam Clin Pharmacol. 2014; 28(3): 323-330.

[5] Hutchinson J, Dalziel JM. Flora of west tropical Africa. Flora West Tropical Africa. 1954; 2: 137.

[6] Irvine FR Woody plants of Ghana. Woody plants of Ghana.1961.

[7] Atif M, Azharuddin M, Rahman SA, Ahmed MI, Mahmood SB.Evaluation of anticataract potential of Waltheria indica in albino rats. Asian J Plant Sci Res. 2014; 4(6): 52-58.

[8] Kannan M, Kumar TS, Rao MV. Antidiabetic and antioxidant properties of Waltheria indica L., an ethnomedicinal plant. Int J Pharma Res Health Sci. 2016; 4(5): 1376-1384.

[9] Oladiji AT, Abdullahi SA, Yakubu MT. Evaluation of haematinic potential of aqueous extract of Waltheria indica L root on rats reared on iron sufficient and iron deficient feeds. Nig J Biochem Mol Biol. 2005; 20(2): 115-122.

[10] Baskaran K, Ranjani R. Aphrodisiac activity of aqueous root extract of Waltheria indica in male Wistar albino rats. Int J Pharmacol Res. 2016; 6(2): 141-143

[11] Monteillier A, Cretton S, Ciclet O, Marcourt L, Ebrahimi SN, Christen P, Cuendet M. Cancer chemopreventive activity of compounds isolated from Waltheria indica. J Ethnopharmacol. 2017; 203: 214-225.

[12] Conventions.coe.int [homepage on the Internet]. Council of Europe. European Convention for the Protection of Vertebrate Animals used for Experimental and other Scientific Purposes.

[13] Sidney D, Simpson TH. The determination of serum bicarbonate by flame photometry. www.sciencedirect.com. 1995

[14] O Schales, SS Schales. "A Simple and Accurate Method for the Determination of Chloride in Biological Fluids," Journal of Biological Chemistry. 1941; 141(3): 879-884.

[15] Margoshes M, Vallee BL. In Meth. biochem. Anal., 3, 353, ed.byGlick,D. Interscience Publishers, NewYorkandLondon. 1956.

[16] Doumas BT, Perry BW, Sasse EA, Straumfjord JV. Standardization in bilirubin assays: evaluation of selected methods and stability of bilirubin solutions. Clin. Chem. 1973; 19: 984-993.

[17] Reitman S, S Frankel. A colorimetric method for the determination of serum glutamic oxaloacetic and glutamic pyruvic transaminases. Am. J. Clin. Pathol. 1957; 28: 56-63.

[18] Bassey OA, Lowry OH, Brock MJ. A Method for the Rapid Determination of Alkaline Phosphates with Five Cubic Millimetres of Serum. Journal of Biological Chemistry. 1946; 164: 321-325.

[19] Seedhom BB, Longton EB, Wright V, et al. Dimensions of the Knee: Radiographic and Autopsy Study of Sizes Required by a Knee Prosthesis. Annals of the Rheumatic Diseases. 1972; 31: 54-58.

[20] Drury RA, Wallington EA. Carleton's Histological Technique. 5th Edition, Oxford University Press, New York. 1980. 